\title{
Induced Pluripotent Stem Cells in Cardiovascular Medicine
}

\author{
Toru Egashira, ${ }^{1}$ Shinsuke Yuasa, ${ }^{1,2}$ and Keiichi Fukuda ${ }^{1}$ \\ ${ }^{1}$ Department of Cardiology, Keio University School of Medicine, 35 Shinanomachi, Shinjuku, Tokyo 160-8582, Japan \\ ${ }^{2}$ Center for Integrated Medical Research, Keio University School of Medicine, 35 Shinanomachi, Shinjuku, Tokyo 160-8582, Japan
}

Correspondence should be addressed to Keiichi Fukuda, kfukuda@sc.itc.keio.ac.jp

Received 22 December 2010; Revised 25 May 2011; Accepted 18 July 2011

Academic Editor: Randall J. Lee

Copyright () 2011 Toru Egashira et al. This is an open access article distributed under the Creative Commons Attribution License, which permits unrestricted use, distribution, and reproduction in any medium, provided the original work is properly cited.

\begin{abstract}
Induced pluripotent stem (iPS) cells are generated by reprogramming human somatic cells through the forced expression of several embryonic stem (ES) cell-specific transcription factors. The potential of iPS cells is having a significant impact on regenerative medicine, with the promise of infinite self-renewal, differentiation into multiple cell types, and no problems concerning ethics or immunological rejection. Human iPS cells are currently generated by transgene introduction principally through viral vectors, which integrate into host genomes, although the associated risk of tumorigenesis is driving research into nonintegration methods. Techniques for pluripotent stem cell differentiation and purification to yield cardiomyocytes are also advancing constantly. Although there remain some unsolved problems, cardiomyocyte transplantation may be a reality in the future. After those problems will be solved, applications of human iPS cells in human cardiovascular regenerative medicine will be envisaged for the future. Furthermore, iPS cell technology has generated new human disease models using disease-specific cells. This paper summarizes the progress of iPS cell technology in cardiovascular research.
\end{abstract}

\section{Introduction}

Cardiovascular disease remains a major cause of mortality in developed countries, with severe heart failure being the leading cause of cardiac death [1]. There is no fundamental therapy for refractory heart failure other than heart transplantation, which is not regarded as a robust option because of the associated problems such as too few donors and immunological rejection [2]. A clear need, therefore, exists for novel therapies for severe cardiovascular disease, and recent advances in stem cell biology have indicated that regenerative medicine might meet that need in the future.

Stem cells are defined by the characteristics of selfrenewal and differentiation capability to multiple tissues. These cells thus hold great promise as a source for cell transplantation therapy. Embryonic organs rapidly develop, and embryonic cells have a strong proliferation potential. In particular, embryonic stem (ES) cells that are established from the inner cell mass of the morula stage of mammalian embryos are regarded as a powerful cell source for clinical application because of their promising growth potential and pluripotency. However, there are major obstacles with the use of human ES cells such as bioethical issues surrounding the destruction of a fertilized egg and immune rejection due to alloantigens following transplantation. Adult organs are also seen as a potential source of somatic stem cells with the ability to proliferate and differentiate into the specific cells in each tissue and thus help to maintain tissue homeostasis and organ healing after injury. Adult heart, for instance, contains cardiac stem cells that can be differentiated into mature cardiomyocytes and vascular cells, and is, therefore, a candidate source for cardiac cell transplantation therapy [3, 4]. However, there are not sufficient numbers of somatic stem cells in adult organs and the proliferation and differentiation ability of somatic stem cells is limiting compared to that of ES cells.

The recent generation of induced pluripotent stem (iPS) cells has created new hope in the field of regenerative medicine for overcoming the dilemma of ES cells. iPS cells can be generated from somatic cells by introducing defined reprogramming factors (Oct3/4, Sox2, Klf4, c-Myc, Nanog, and Lin28) in various mammals including mouse, rat, pig, monkey, and human [5-10]. These cells have the two crucial stem cell characteristics of self-renewal and pluripotency. In addition, the ethical issues associated with generating iPS cells are trivial compared to those for ES cells because 
the sacrifice of an embryo is dispensable, and the use of the recipient's own cells eliminates the risk of immune rejection generally associated with transplantation. Because of these tremendous benefits, iPS cells hold great promise as a novel cell source for regenerative medicine. Moreover, the unique characteristics harbored in the genetic information of almost every adult cell could allow the creation of patient-specific pluripotent stem cells, which can be then dedicated to any cell type in vitro. Consequently, iPS cell technology has raised concerns in the fields of disease pathogenesis and drug discovery [11-13].

\section{2. iPS Induction Methods}

ES cells have the ability to proliferate infinitely and can differentiate into the cell types of all three germ layers with germ line transmission [14]. The first human ES cells were successfully generated in 1998 [15]. Human iPS cells were established in 2007 by the transduction of various gene cocktails $[6,7]$. The characteristics of iPS cells are quite similar to those of ES cells in terms of morphology, proliferation ability, patterning of global gene expression, and the epigenetic status of promoter regions for stem-cellspecific transcription factors. As a matter of course, these iPS cells also can differentiate into cells of the three germ layers in vitro and in vivo.

For iPS cell technology to realize its significant promise for advanced regenerative medicine, several difficult problems must be addressed. The original method of generating iPS cells involves the transduction of core transcription factors into somatic cells by retroviral vectors with the accompanying insertion of transgenes into the host genome. These transgenes could theoretically disrupt the native genes and/or alter normal gene expression. Although the expression of such viral-mediated exogenous genes are virtually silenced once the cells are fully reprogrammed into iPS cells, small but sustained leakage of transgene expression or the reactivation of those transgenes occasionally disturbs the differentiation and maintenance of an undifferentiated state [16]. In particular, oncogenic transgene reactivation such as that of $c-M y c$ could increase the risk of tumor formation after transplantation of the iPS-derived cells [17]. In addition, the detail mechanism of reprogramming is not yet elucidated sufficiently, and the reprogramming efficiency of somatic cells is still low. These problems need to be at least minimized before the application of iPS technology in the clinical setting can proceed.

To establish safer iPS cells, several novel methods are being investigated that do not involve transgene insertions into the host genome. Various gene-delivery systems have been developed for the reprogramming of human somatic cells into iPS cells [18-24]. In addition, some chemical compounds can raise the reprogramming efficiency and reduce the required number of the transducing factors to generate iPS cells [25-28]. There are many reports of somatic cells being reprogrammed to iPS cells, although most cases involve dermal fibroblasts obtained from a dermal punch biopsy, which leaves a small scar on the donor's skin. Such skin biopsies should be avoided to generate human iPS cells. Recently, we and several other groups reported novel methods for generating iPS cells less invasively from human circulating peripheral blood cells [29-32]. Our method uses Sendai viral systems to deliver the reprogramming factors [33]. Sendai virus is categorized as a negative-strand RNA virus that cannot integrate into the host genome, but can highly infect activated $\mathrm{T}$ cells [34]. It is very important for human clinical usage to obtain the nonintegration human iPS cell easily, stably, and efficiently and attenuate the physical invasion for donors to obtain somatic cells. These improved methods can be helpful to extend the indication of generating iPS cells and to be easily accessible to realize the future clinical application of the iPS technology.

\section{Differentiation into Cardiomyocytes from Pluripotent Stem Cells}

ES cells and iPS cells can give rise to all cell types of all three germ layers, using quite similar methodologies to control the differentiation. In the conventional method, ES cell differentiation is performed through embryoid bodies (EBs), which are aggregates of ES cells maintained in suspension cultures. In this section, we focus on the differentiation systems for generating cardiomyocytes from ES cells and iPS cells.

A recent report indicated no significant difference in the fundamental characteristics of cardiomyocytes differentiated from either ES or iPS cells [35-38]. However, the efficiency of cardiogenesis from ES and iPS cells is still too low and not sufficiently stable to realize the goals of cardiac regenerative medicine. Generally considered, the mechanisms of in vitro differentiation from pluripotent stem cells are similar to the regulatory mechanisms of normal early development. To improve the efficiency of in vitro cardiogenesis, various screens for essential signalling molecules in normal heart development have been performed. Among several signal proteins associated with cardiac development, canonical Wnt/beta-catenin [39-42], activin/nodal [43, 44], and BMP signaling [45-51] have the crucial roles in normal heart development, and supplementation of those molecules into ES/iPS cell differentiation systems could significantly boost the efficiency of cardiogenesis. Moreover, it also seems that bidirectional stimulation in these pathways is necessary at different developmental stages $[52,53]$.

We previously reported that transit inhibition of BMP signaling very early during differentiation is crucial for cardiogenesis in murine ES cells [54]. Whole-mount in situ hybridization for various BMP antagonists on mouse embryos at different developmental stages revealed that noggin, a BMP antagonist, was expressed only briefly in the heart-forming area. This phenomenon was also observed in early embryos of chick and Xenopus, suggesting a conserved mechanism in heart development $[55,56]$. We proposed that administration of noggin before the EB formation stage would mimic its transient and strong expression during early gastrulation. Indeed, noggin administration around EB formation day led to a marked increase in cardiogenesis 
from murine ES cells. Other BMP antagonists also act to increase cardiomyocyte differentiation efficiency, indicating that transient relief from the intrinsic BMP signal is critical for cardiomyocyte induction.

We also identified growth factors crucial for embryonic premature cardiomyocytes through the screening of global gene expressions in noggin-treated mouse ES cellderived cardiomyocytes by microarray analysis [57]. We found that the expression level of $c s f 3 r$, which encodes the granulocyte colony-stimulating factor receptor (G-CSFR), was significantly higher in cardiomyocyte-differentiating ES cells [58], and confirmed that both G-CSFR and G-CSF were specifically but transiently expressed in embryonic mouse heart at the midgestational stage. When extrinsic G-CSF was administered to ES/iPS cell-derived cardiomyocytes, it markedly augmented their proliferation. These findings indicated that G-CSF is critical for cardiomyocyte proliferation and could be used to boost the yield of cardiomyocytes from $\mathrm{ES} / \mathrm{iPS}$ cells for their potential application in regenerative medicine.

To some extent, we can manage to differentiate pluripotent stem cells into cardiomyocytes effectively and control the proliferation of premature cardiomyocytes. However, human heart is a large organ, and huge numbers of cardiomyocytes would be needed for human cardiac regenerative therapy, requiring even more sophisticated methods for cardiomyocyte generation. To this end, prominent differences have been demonstrated in the ability to differentiate into specific lineage cells among iPS cell [59]. Moreover, their response to various growth factor and cytokine stimulations also varied markedly among cell lines. Recent studies have also demonstrated that the characteristics of iPS cells are influenced by the derived somatic cells according to their epigenetic memory [60-62]. It would, therefore, be preferable to ascertain which cell lines are the best sources of iPS cells for each lineage cell differentiation and what is the best way to select such iPS cell lines before starting the differentiation.

\section{Stem Cell-Based Cardiac Regeneration}

ES and iPS cells both have the potential to be a definite cell source for regenerative therapy because they can proliferate infinitely. In the cardiovascular field, regenerative cell therapy using pluripotent cells is expected to complement rather than replace heart transplantation in the future $[12,63,64]$. Molecular biological and physiological studies have demonstrated that ES and iPS cell-derived cardiomyocytes have the required cardiovascular function [65-67]. iPS cells can differentiate into several types of cardiomyocytes including atrial, nodal, and ventricular cells, with similar properties to native cardiomyocytes. Cardiomyocytes derived from iPS cells properly express typical ion channels with the expected functional responses to several ion channel blockers [68]. There are also many reports that the transplantation of either cardiomyocytes or cardiac progenitor cells derived from human ES cells into infarcted rodent heart could improve cardiac function $[50,69,70]$. Transplanted ES/iPS cellderived cardiomyocytes were integrated into the infarcted host heart and supplied working muscles functioning cooperatively, while the molecules secreted in a paracrine or autocrine fashion from transplanted cells are also important. It was also reported that the transplantation of iPS cells into the postinfarcted heart of immunocompetent mouse significantly recovered the cardiac function of failing heart and transplanted cells were successfully differentiated into cardiomyocytes, smooth muscles, and endothelial cells in the heart [71]. The precise mechanisms underpinning these successful cell transplantations remain unclear. However, accumulating evidence indicates that the transplantation of iPS cell-derived cardiomyocytes will be a viable future alternative for treating diseased heart.

One of the most critical issues in these efforts is how to eliminate undifferentiated ES/iPS cells from the transplanting cells. Undifferentiated pluripotent stem cells implanted into the recipient body increase concerns about tumors like teratoma emerging from the transplanted cells [72]. Although it is not yet determined whether terminally differentiated cells or progenitor cells are better for cell transplants, undifferentiated pluripotent stem cells need to be eliminated from the equation before transplantation in any case to relieve the risk of tumorigenesis. A variety of purification methods for ES/iPS cell-derived differentiated cells have been developed, with most involving gene manipulation to label the selection marker such as GFP regulated under a specific promoter $[73,74]$. However, gene modification in itself could also induce tumorigenesis. The ideal method to purify the cells would, therefore, not use genetic manipulation. We recently obtained highly pure ( $>99 \%$ purity) human ES/iPS cell-derived cardiomyocytes by fluorescence-activated cell sorting with the fluorescent dye that labels mitochondria [75]. This method involves no gene modification and could be used in the clinical setting. In addition, cell surface proteins in nascent cardiomyocytes and cardiomyogenic progenitors have been defined as non genetic selection markers for cardiomyocytes in the mouse ES/iPS cells [43, 76-80]. Such methodology to purify the objective cells is constantly advancing the goals for cardiac regenerative therapy. Long-term followup is necessary to analyze recipient safety and prognosis, and all cell transplantation should be tested in a large animal model before clinical usage.

\section{Genetic and Epigenetic Profile of iPS Cell and iPS Cell-Derived Cardiomyocyte}

There are several concerns about using iPS cell for regenerative medicine, because accumulating genetic and epigenetic profiles proved there remain important problems. Initial study about epigenetic memory showed that iPS cells derived from adult murine tissues harbour residual DNA methylation signatures characteristic of their somatic tissue of origin, which favours their differentiation along lineages related to the donor cell, which suggest an epigenetic memory of the tissue of origin that may have influence on directed differentiation for applications in disease modelling or treatment [61]. In terms of pluripotent stem cellderived cardiomyocyte, iPS cell-derived cardiomyocytes are 
transcriptionally highly similar to ES cell-derived cardiomyocytes, but iPS cell-derived cardiomyocyte also still possesses the same somatic signature [81]. Exome analysis revealed that hiPS cells acquire genetic modifications in addition to epigenetic modifications which suggest extensive genetic screening should become a standard procedure to ensure hiPS cell safety before clinical usage [82]. Surprisingly latest research showed that abnormal gene expression in some cells differentiated from iPSCs can induce T-cell-dependent immune response in syngeneic recipients in contrast to derivatives of ESCs [83]. The expression of these abnormal minor antigens also may be due to epigenetic difference between iPS cells and ES cells. These data suggests that extensive genetic and epigenetic screening should become a standard procedure to ensure hiPS cell safety before clinical use.

\section{Investigation of Patient-Specific iPS Cells}

Another expectation for iPS cells is the generation of human disease-specific pluripotent stem cells, since established iPS cells have identical genetic mutations to the source tissue. Patient-specific iPS cells can differentiate into any type of cell, allowing us to directly and repetitively analyse the diseased cells in vitro. We now need to establish a revolutionary assay system to elucidate the disease pathogenesis and to use these patient-specific cells as a novel tool for drug screening in combination with personalized medicine. Generally, it is difficult or impossible to take large samples from specific patient tissues like neurons and cardiomyocytes and, even if possible, such terminally differentiated cells cannot proliferate sufficiently in vitro. For that reason, researchers in this field eagerly await this kind of promising stem cell.

To date, many kinds of patient-specific iPS cells have been generated to diseases such as adenosine deaminase deficiency, the Schwachman-Bodian-Diamond syndrome, Gaucher's disease, the Duchenne and Becker muscular dystrophy, Parkinson's disease, Huntington's disease, type 1 diabetes mellitus, Down's syndrome, the Lesch-Nyhan syndrome, amyotrophic lateral sclerosis, spinal muscular atrophy, and Fanconi's anemia [84-88]. According to these previous reports, iPS cells generated from a patient suffering from early-onset disease are more likely to closely reproduce the disease phenotypes. Recently, cardiac disease-specific iPS cells were also reported. One line is specific for the LEOPARD syndrome, which is an autosomal dominant developmental disorder belonging to a relatively prevalent class of inherited RAS-mitogen-activated protein kinase signalling diseases with pleomorphic effects on several tissues and organ systems [89]. The patient has a mutation in the PTPN11 gene, which encodes the SHP2 phosphatase. A major disease phenotype in patients with the LEOPARD syndrome is hypertrophic cardiomyopathy. This study showed that cardiomyocytes derived from LEOPARD syndrome iPS cells are spontaneously hypertrophied in vitro and have a higher degree of sarcomeric organization compared with cardiomyocytes derived from human ES cells or wild-type iPS cells. They concluded that these features correlate with a potential hypertrophic state in patients. The other reported diseasespecific iPS cell line mimics congenital long QT syndromes (LQTs) [90], which are heritable diseases associated with prolongation of the QT interval on an electrocardiogram and a high risk of sudden cardiac death due to ventricular tachyarrhythmia. The authors generated iPS cells from two patients with LQTs type 1 (LQTs 1 ), who have mutations in the KCNQ1 gene encoding the repolarizing potassium channel mediating the delayed rectifier I (Ks) current. Individual cardiomyocytes derived from LQTs 1 patients showed prolonged action potentials compared with cells from control subjects. Moreover, cardiomyocytes derived from patients with LQTs 1 had an increased susceptibility to catecholamine-induced tachyarrhythmia, and the phenotype was attenuated by beta-blockade, which is one of the most important clinical features of these syndromes. The study showed that LQTs 1 patient-specific iPS cell-derived cardiomyocytes totally reproduced the diseased phenotypes in a clinical setting.

These studies into patient-specific iPS cells indicate a tremendous potential for our increased understanding of pathogenesis. Such technologies will be the basis for novel industries in drug development and diagnostics.

\section{Conclusions}

Although iPS cells are artificial pluripotent stem cells, they can produce chimeric animals in mouse and rat, and a tetraploid complementation experiment demonstrated that mouse iPS cells have the ability to autonomously generate full-term mice. These results clarified the existence of pure pluripotent stem cells in iPS cells. Methods for the generation of iPS cells have now undergone tremendous and steady improvements. Although some problems remain such as genetic mutation during reprogramming, incomplete epigenetic reprogramming, and undesired gene expression, iPS cells could be applicable for regenerative medicine in the future after solving those problems. Studies of disease pathogenesis and drug discovery using this technology have already been undertaken and will shed light on the discovery of novel treatments for fatal cardiovascular diseases.

\section{References}

[1] S. Neubauer, "The failing heart—an engine out of fuel," New England Journal of Medicine, vol. 356, no. 11, pp. 1140-1151, 2007.

[2] D. Mancini and K. Lietz, "Selection of cardiac transplantation candidates in 2010," Circulation, vol. 122, no. 2, pp. 173-183, 2010.

[3] L. Bu, X. Jiang, S. Martin-Puig et al., "Human ISL1 heart progenitors generate diverse multipotent cardiovascular cell lineages," Nature, vol. 460, no. 7251, pp. 113-117, 2009.

[4] A. P. Beltrami, L. Barlucchi, D. Torella et al., "Adult cardiac stem cells are multipotent and support myocardial regeneration," Cell, vol. 114, no. 6, pp. 763-776, 2003.

[5] K. Takahashi and S. Yamanaka, "Induction of pluripotent stem cells from mouse embryonic and adult fibroblast cultures by defined factors," Cell, vol. 126, no. 4, pp. 663-676, 2006. 
[6] K. Takahashi, K. Tanabe, M. Ohnuki et al., "Induction of pluripotent stem cells from adult human fibroblasts by defined factors," Cell, vol. 131, no. 5, pp. 861-872, 2007.

[7] J. Yu, M. A. Vodyanik, K. Smuga-Otto et al., "Induced pluripotent stem cell lines derived from human somatic cells," Science, vol. 318, no. 5858, pp. 1917-1920, 2007.

[8] J. Liao, C. Cui, S. Chen et al., "Generation of induced pluripotent stem cell lines from adult rat cells," Cell Stem Cell, vol. 4, no. 1, pp. 11-15, 2009.

[9] M. A. Esteban, J. Xu, J. Yang et al., "Generation of induced pluripotent stem cell lines from Tibetan miniature pig," Journal of Biological Chemistry, vol. 284, no. 26, pp. 1763417640, 2009.

[10] I. Tomioka, T. Maeda, H. Shimada et al., "Generating induced pluripotent stem cells from common marmoset (Callithrix jacchus) fetal liver cells using defined factors, including Lin28," Genes to Cells, vol. 15, no. 9, pp. 959-969, 2010.

[11] S. Yuasa and K. Fukuda, "Cardiac regenerative medicine," Circulation Journal, vol. 72, pp. A49-A55, 2008.

[12] S. Yuasa and K. Fukuda, "Recent advances in cardiovascular regenerative medicine: the induced pluripotent stem cell era," Expert Review of Cardiovascular Therapy, vol. 6, no. 6, pp. 803810, 2008.

[13] Y. Yoshida and S. Yamanaka, "IPS cells: a source of cardiac regeneration," Journal of Molecular and Cellular Cardiology, vol. 50, no. 2, pp. 327-332, 2011.

[14] M. J. Evans and M. H. Kaufman, "Establishment in culture of pluripotential cells from mouse embryos,” Nature, vol. 292, no. 5819, pp. 154-156, 1981.

[15] J. A. Thomson, "Embryonic stem cell lines derived from human blastocysts," Science, vol. 282, no. 5391, pp. 1145-1147, 1998.

[16] T. Brambrink, R. Foreman, G. G. Welstead et al., "Sequential expression of pluripotency markers during direct reprogramming of mouse somatic cells," Cell Stem Cell, vol. 2, no. 2, pp. 151-159, 2008.

[17] K. Okita, T. Ichisaka, and S. Yamanaka, "Generation of germline-competent induced pluripotent stem cells," Nature, vol. 448, no. 7151, pp. 313-317, 2007.

[18] W. Zhou and C. R. Freed, "Adenoviral gene delivery can reprogram human fibroblasts to induced pluripotent stem cells," Stem Cells, vol. 27, no. 11, pp. 2667-2674, 2009.

[19] J. Yu, K. Hu, K. Smuga-Otto et al., "Human induced pluripotent stem cells free of vector and transgene sequences," Science, vol. 324, no. 5928, pp. 797-801, 2009.

[20] K. Kaji, K. Norrby, A. Paca, M. Mileikovsky, P. Mohseni, and K. Woltjen, "Virus-free induction of pluripotency and subsequent excision of reprogramming factors," Nature, vol. 458, no. 7239, pp. 771-775, 2009.

[21] K. Woltjen, I. P. Michael, P. Mohseni et al., "PiggyBac transposition reprograms fibroblasts to induced pluripotent stem cells," Nature, vol. 458, no. 7239, pp. 766-770, 2009.

[22] H. Zhou, S. Wu, J. Y. Joo et al., "Generation of induced pluripotent stem cells using recombinant proteins," Cell Stem Cell, vol. 4, no. 5, pp. 381-384, 2009.

[23] D. Kim, C. H. Kim, J. I. Moon et al., "Generation of human induced pluripotent stem cells by direct delivery of reprogramming proteins," Cell Stem Cell, vol. 4, no. 6, pp. 472476, 2009.

[24] L. Warren, P. D. Manos, T. Ahfeldt et al., "Highly efficient reprogramming to pluripotency and directed differentiation of human cells with synthetic modified mRNA," Cell Stem Cell, vol. 7, no. 5, pp. 618-630, 2010.
[25] Y. Xu, Y. Shi, and S. Ding, "A chemical approach to stem-cell biology and regenerative medicine," Nature, vol. 453, no. 7193, pp. 338-344, 2008.

[26] D. Huangfu, R. Maehr, W. Guo et al., "Induction of pluripotent stem cells by defined factors is greatly improved by smallmolecule compounds," Nature Biotechnology, vol. 26, no. 7, pp. 795-797, 2008.

[27] N. Urasawa, M. R. Wada, N. Machida et al., "Selective vacuolar degeneration in dystrophin-deficient canine Purkinje fibers despite preservation of dystrophin-associated proteins with overexpression of Dp71," Circulation, vol. 117, no. 19, pp. 2437-2448, 2008.

[28] H. J. Cho, C. S. Lee, Y. W. Kwon et al., "Induction of pluripotent stem cells from adult somatic cells by proteinbased reprogramming without genetic manipulation," Blood, vol. 116, no. 3, pp. 386-395, 2010.

[29] A. Kunisato, M. Wakatsuki, H. Shinba, T. Ota, I. Ishida, and K. Nagao, "Direct generation of induced pluripotent stem cells from human nonmobilized blood," Stem Cells and Development, vol. 20, no. 1, pp. 159-168, 2011.

[30] J. Staerk, M. M. Dawlaty, Q. Gao et al., "Reprogramming of human peripheral blood cells to induced pluripotent stem cells," Cell stem cell, vol. 7, no. 1, pp. 20-24, 2010.

[31] Y. H. Loh, O. Hartung, H. Li et al., "Reprogramming of T cells from human peripheral blood," Cell stem cell, vol. 7, no. 1, pp. 15-19, 2010.

[32] M. E. Brown, E. Rondon, D. Rajesh et al., "Derivation of induced pluripotent stem cells from human peripheral blood T lymphocytes," PLoS One, vol. 5, no. 6, Article ID e11373, 2010.

[33] T. Seki, S. Yuasa, M. Oda et al., "Generation of induced pluripotent stem cells from human terminally differentiated circulating T cells," Cell stem cell, vol. 7, no. 1, pp. 11-14, 2010.

[34] S. Okano, Y. Yonemitsu, S. Nagata et al., "Recombinant Sendai virus vectors for activated T lymphocytes," Gene Therapy, vol. 10, no. 16, pp. 1381-1391, 2003.

[35] L. W. Van Laake, L. Qian, P. Cheng et al., "Reporter-based isolation of induced pluripotent stem cell-and embryonic stem cell-derived cardiac progenitors reveals limited gene expression variance," Circulation Research, vol. 107, no. 3, pp. 340-347, 2010.

[36] J. Xi, M. Khalil, N. Shishechian et al., "Comparison of contractile behavior of native murine ventricular tissue and cardiomyocytes derived from embryonic or induced pluripotent stem cells," FASEB Journal, vol. 24, no. 8, pp. 2739-2751, 2010.

[37] N. Yokoo, S. Baba, S. Kaichi et al., "The effects of cardioactive drugs on cardiomyocytes derived from human induced pluripotent stem cells," Biochemical and Biophysical Research Communications, vol. 387, no. 3, pp. 482-488, 2009.

[38] A. Kuzmenkin, H. Liang, G. Xu et al., "Functional characterization of cardiomyocytes derived from murine induced pluripotent stem cells in vitro," FASEB Journal, vol. 23, no. 12, pp. 4168-4180, 2009.

[39] S. Ueno, G. Weidinger, T. Osugi et al., "Biphasic role for Wnt/ $\beta$-catenin signaling in cardiac specification in zebrafish and embryonic stem cells," Proceedings of the National Academy of Sciences of the United States of America, vol. 104, no. 23, pp. 9685-9690, 2007.

[40] A. T. Naito, I. Shiojima, H. Akazawa et al., "Developmental stage-specific biphasic roles of $\mathrm{Wnt} / \beta$-catenin signaling in cardiomyogenesis and hematopoiesis," Proceedings of the National Academy of Sciences of the United States of America, vol. 103, no. 52, pp. 19812-19817, 2006. 
[41] L. Lin, L. Cui, W. Zhou et al., " $\beta$-Catenin directly regulates Islet 1 expression in cardiovascular progenitors and is required for multiple aspects of cardiogenesis," Proceedings of the National Academy of Sciences of the United States of America, vol. 104, no. 22, pp. 9313-9318, 2007.

[42] A. Klaus, Y. Saga, M. M. Taketo, E. Tzahor, and W. Birchmeier, "Distinct roles of Wnt/ $\beta$-catenin and Bmp signaling during early cardiogenesis," Proceedings of the National Academy of Sciences of the United States of America, vol. 104, no. 47, pp. 18531-18536, 2007.

[43] L. Yang, M. H. Soonpaa, E. D. Adler et al., "Human cardiovascular progenitor cells develop from a KDR+ embryonic-stemcell-derived population," Nature, vol. 453, no. 7194, pp. 524528, 2008.

[44] S. Parisi, D. D’Andrea, C. T. Lago, E. D. Adamson, M. G. Persico, and G. Minchiotti, "Nodal-dependent Cripto signaling promotes cardiomyogenesis and redirects the neural fate of embryonic stem cells," Journal of Cell Biology, vol. 163, no. 2, pp. 303-314, 2003.

[45] P. Zhang, J. Li, Z. Tan et al., "Short-term BMP-4 treatment initiates mesoderm induction in human embryonic stem cells," Blood, vol. 111, no. 4, pp. 1933-1941, 2008.

[46] D. Kami, I. Shiojima, H. Makino et al., "Gremlin enhances the determined path to cardiomyogenesis," PLoS One, vol. 3, no. 6, Article ID e2407, 2008.

[47] S. Hong, J. K. Kang, C. J. Bae, E. S. Ryu, S. H. Lee, and J. H. Lee, "Dovelopment of efficient cardiac differentiation method of mouse embryonic stem cells," Key Engineering Materials, vol. 342-343, pp. 25-28, 2007.

[48] D. Kumar and B. Sun, "Transforming growth factor- $\beta 2$ enhances differentiation of cardiac myocytes from embryonic stem cells," Biochemical and Biophysical Research Communications, vol. 332, no. 1, pp. 135-141, 2005.

[49] A. Behfar, L. V. Zingman, D. M. Hodgson et al., "Stem cell differentiation requires a paracrine pathway in the heart," FASEB Journal, vol. 16, no. 12, pp. 1558-1566, 2002.

[50] M. A. Laflamme, K. Y. Chen, A. V. Naumova et al., "Cardiomyocytes derived from human embryonic stem cells in pro-survival factors enhance function of infarcted rat hearts," Nature Biotechnology, vol. 25, no. 9, pp. 1015-1024, 2007.

[51] J. Hao, M. A. Daleo, C. K. Murphy et al., "Dorsomorphin, a selective small molecule inhibitor of BMP signaling, promotes cardiomyogenesis in embryonic stem cells," PLoS One, vol. 3, no. 8, Article ID e2904, 2008.

[52] T. Sumi, N. Tsuneyoshi, N. Nakatsuji, and H. Suemori, "Defining early lineage specification of human embryonic stem cells by the orchestrated balance canonical Wnt $\beta$ catenin, activin/Nodal and BMP signaling," Development, vol. 135, no. 17, pp. 2969-2979, 2008.

[53] S. L. Paige, T. Osugi, O. K. Afanasiev, L. Pabon, H. Reinecke, and C. E. Murry, "Endogenous Wnt/ $\beta$-catenin signaling is required for cardiac differentiation in human embryonic stem cells," PloS One, vol. 5, no. 6, Article ID e11134, 2010.

[54] S. Yuasa, Y. Itabashi, U. Koshimizu et al., "Transient inhibition of BMP signaling by Noggin induces cardiomyocyte differentiation of mouse embryonic stem cells," Nature Biotechnology, vol. 23, no. 5, pp. 607-611, 2005.

[55] S. Faure, P. De Santa Barbara, D. J. Roberts, and M. Whitman, "Endogenous patterns of BMP signaling during early chick development," Developmental Biology, vol. 244, no. 1, pp. 4465, 2002.
[56] R. B. Fletcher, A. L. Watson, and R. M. Harland, "Expression of Xenopus tropicalis noggin 1 and noggin 2 in early development: two noggin genes in a tetrapod," Gene Expression Patterns, vol. 5, no. 2, pp. 225-230, 2004.

[57] S. Yuasa, T. Onizuka, K. Shimoji et al., "Zacl is an essential transcription factor for cardiac morphogenesis," Circulation Research, vol. 106, no. 6, pp. 1083-1091, 2010.

[58] K. Shimoji, S. Yuasa, T. Onizuka et al., "G-CSF promotes the proliferation of developing cardiomyocytes in vivo and in derivation from ESCs and iPSCs," Cell Stem Cell, vol. 6, no. 3, pp. 227-237, 2010.

[59] B. Y. Hu, J. P. Weick, J. Yu et al., "Neural differentiation of human induced pluripotent stem cells follows developmental principles but with variable potency," Proceedings of the National Academy of Sciences of the United States of America, vol. 107, no. 9, pp. 4335-4340, 2010.

[60] J. M. Polo, S. Liu, M. E. Figueroa et al., "Cell type of origin influences the molecular and functional properties of mouse induced pluripotent stem cells," Nature Biotechnology, vol. 28, no. 8, pp. 848-855, 2010.

[61] K. Kim, A. Doi, B. Wen et al., "Epigenetic memory in induced pluripotent stem cells," Nature, vol. 467, no. 7313, pp. 285290, 2010.

[62] Q. Hu, A. M. Friedrich, L. V. Johnson, and D. O. Clegg, "Memory in induced pluripotent stem cells: reprogrammed human retinal-pigmented epithelial cells show tendency for spontaneous redifferentiation," Stem Cells, vol. 28, no. 11, pp. 1981-1991, 2010.

[63] K. Fukuda and S. Yuasa, "Stem cells as a source of regenerative cardiomyocytes," Circulation Research, vol. 98, no. 8, pp. 10021013, 2006.

[64] Y.-H. Choi, T. Saric, B. Nasseri et al., "Cardiac cell therapies: the next generation," Cardiovascular Therapeutics, vol. 29, no. 1, pp. 2-16, 2011.

[65] I. Kehat, D. Kenyagin-Karsenti, M. Snir et al., "Human embryonic stem cells can differentiate into myocytes with structural and functional properties of cardiomyocytes," Journal of Clinical Investigation, vol. 108, no. 3, pp. 407-414, 2001.

[66] J. Zhang, G. F. Wilson, A. G. Soerens et al., "Functional cardiomyocytes derived from human induced pluripotent stem cells," Circulation Research, vol. 104, no. 4, pp. e30-e41, 2009.

[67] L. Zwi, O. Caspi, G. Arbel et al., "Cardiomyocyte differentiation of human induced pluripotent stem cells," Circulation, vol. 120, no. 15, pp. 1513-1523, 2009.

[68] T. Tanaka, S. Tohyama, M. Murata et al., "In vitro pharmacologic testing using human induced pluripotent stem cellderived cardiomyocytes," Biochemical and Biophysical Research Communications, vol. 385, no. 4, pp. 497-502, 2009.

[69] L. W. Van Laake, R. Passier, P. A. Doevendans, and C. L. Mummery, "Human embryonic stem cell-derived cardiomyocytes and cardiac repair in rodents," Circulation Research, vol. 102, no. 9, pp. 1008-1010, 2008.

[70] O. Caspi, I. Huber, I. Kehat et al., "Transplantation of human embryonic stem cell-derived cardiomyocytes improves myocardial performance in infarcted rat hearts," Journal of the American College of Cardiology, vol. 50, no. 19, pp. 1884-1893, 2007.

[71] T. J. Nelson, A. Martinez-Fernandez, S. Yamada, C. PerezTerzic, Y. Ikeda, and A. Terzic, "Repair of acute myocardial infarction with induced pluripotent stem cells induced by human stemness factors," Circulation, vol. 120, no. 5, pp. 408416, 2009. 
[72] K. Miura, Y. Okada, T. Aoi et al., "Variation in the safety of induced pluripotent stem cell lines," Nature Biotechnology, vol. 27, no. 8, pp. 743-745, 2009.

[73] S. J. Kinder, T. E. Tsang, G. A. Quinlan, A. K. Hadjantonakis, A. Nagy, and P. P. L. Tam, "The orderly allocation of mesodermal cells to the extraembryonic structures and the anteroposterior axis during gastrulation of the mouse embryo," Development, vol. 126, no. 21, pp. 4691-4701, 1999.

[74] S. J. Kattman, T. L. Huber, and G. Keller, "Multipotent Flk-1+ cardiovascular progenitor cells give rise to the cardiomyocyte, endothelial, and vascular smooth muscle lineages," Developmental Cell, vol. 11, no. 5, pp. 723-732, 2006.

[75] F. Hattori, H. Chen, H. Yamashita et al., "Nongenetic method for purifying stem cell-derived cardiomyocytes," Nature Methods, vol. 7, no. 1, pp. 61-66, 2010.

[76] K. Hidaka, M. Shirai, J. K. Lee et al., "The cellular prion protein identifies bipotential cardiomyogenic progenitors," Circulation Research, vol. 106, no. 1, pp. 111-119, 2010.

[77] J. K. Yamashita, M. Takano, M. Hiraoka-Kanie et al., "Prospective identification of cardiac progenitors by a novel single cellbased cardiomyocyte induction," FASEB Journal, vol. 19, no. 11, pp. 1534-1536, 2005.

[78] T. J. Nelson, R. S. Faustino, A. Chiriac, R. Crespo-Diaz, A. Behfar, and A. Terzic, "CXCR $4^{+} / \mathrm{FLK}-1^{+}$biomarkers select a cardiopoietic lineage from embryonic stem cells," Stem Cells, vol. 26, no. 6, pp. 1464-1473, 2008.

[79] G. Blin, D. Nury, S. Stefanovic et al., "A purified population of multipotent cardiovascular progenitors derived from primate pluripotent stem cells engrafts in postmyocardial infarcted nonhuman primates," Journal of Clinical Investigation, vol. 120, no. 4, pp. 1125-1139, 2010.

[80] J. Leschik, S. Stefanovic, B. Brinon, and M. Pucéat, "Cardiac commitment of primate embryonic stem cells," Nature Protocols, vol. 3, no. 9, pp. 1381-1387, 2008.

[81] M. K. Gupta, D. J. Illich, A. Gaarz et al., "Global transcriptional profiles of beating clusters derived from human induced pluripotent stem cells and embryonic stem cells are highly similar," BMC Developmental Biology, vol. 10, article no. 98, 2010.

[82] A. Gore, Z. Li, H.-L. Fung et al., "Somatic coding mutations in human induced pluripotent stem cells," Nature, vol. 471, no. 7336, pp. 63-67, 2011.

[83] T. Zhao, Z.-N. Zhang, Z. Rong, and Y. Xu, "Immunogenicity of induced pluripotent stem cells," Nature, vol. 474, no. 7350, pp. 212-216, 2011.

[84] I. H. Park, N. Arora, H. Huo et al., "Disease-specific induced pluripotent stem cells,” Cell, vol. 134, no. 5, pp. 877-886, 2008.

[85] F. Soldner, D. Hockemeyer, C. Beard et al., "Parkinson's disease patient-derived induced pluripotent stem cells free of viral reprogramming factors," Cell, vol. 136, no. 5, pp. 964-977, 2009.

[86] J. T. Dimos, K. T. Rodolfa, K. K. Niakan et al., "Induced pluripotent stem cells generated from patients with ALS can be differentiated into motor neurons," Science, vol. 321, no. 5893, pp. 1218-1221, 2008.

[87] A. D. Ebert, J. Yu, F. F. Rose et al., "Induced pluripotent stem cells from a spinal muscular atrophy patient," Nature, vol. 457, no. 7227, pp. 277-280, 2009.

[88] Á. Raya, I. Rodríguez-Piz, G. Guenechea et al., "Diseasecorrected haematopoietic progenitors from Fanconi anaemia induced pluripotent stem cells," Nature, vol. 460, no. 7251, pp. 53-59, 2009.

[89] X. Carvajal-Vergara, A. Sevilla, S. L. Dsouza et al., "Patientspecific induced pluripotent stem-cell-derived models of
LEOPARD syndrome," Nature, vol. 465, no. 7299, pp. 808812,2010 .

[90] A. Moretti, M. Bellin, A. Welling et al., "Patient-specific induced pluripotent stem-cell models for long-QT syndrome," New England Journal of Medicine, vol. 363, no. 15, pp. 13971409, 2010. 

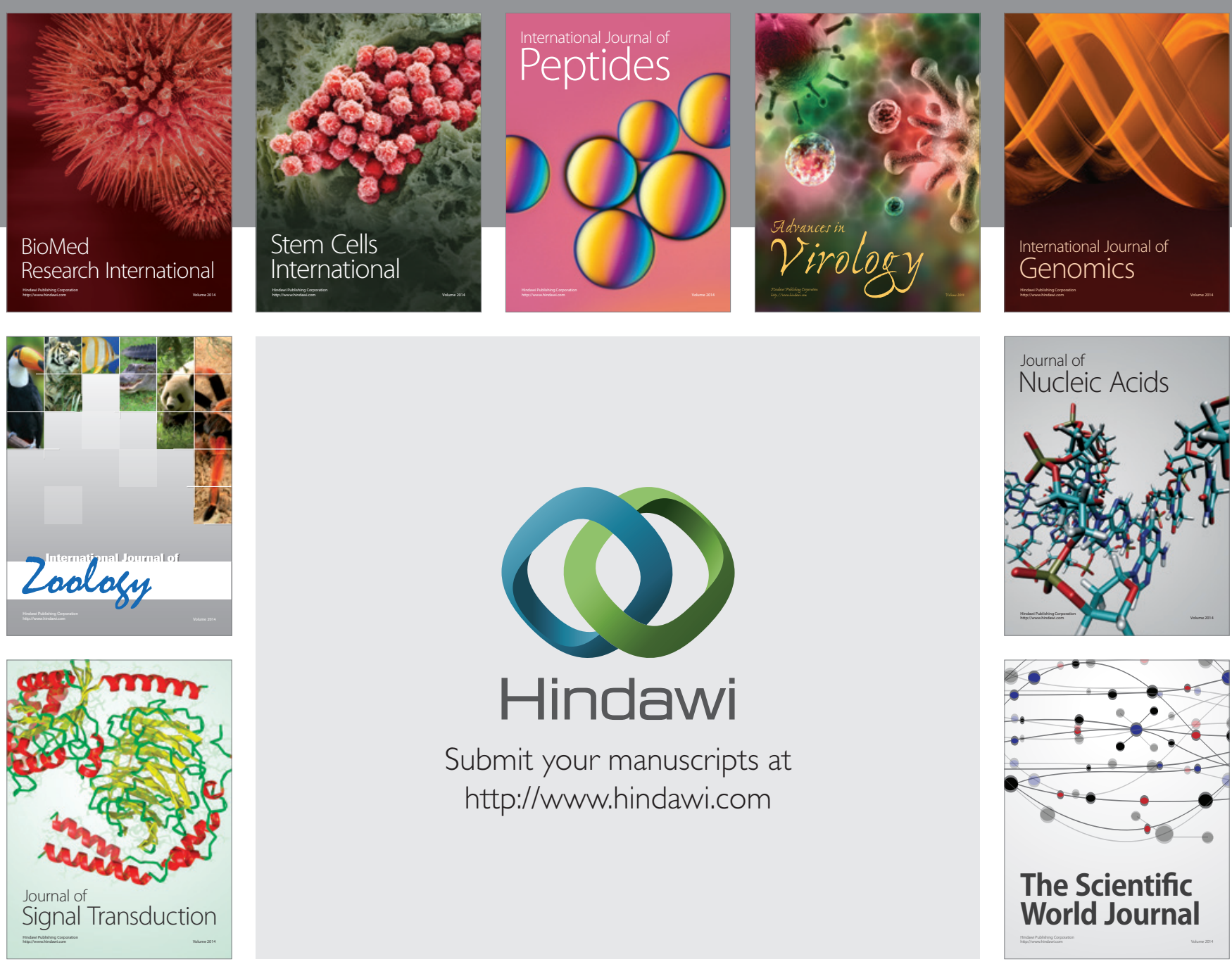

Submit your manuscripts at

http://www.hindawi.com
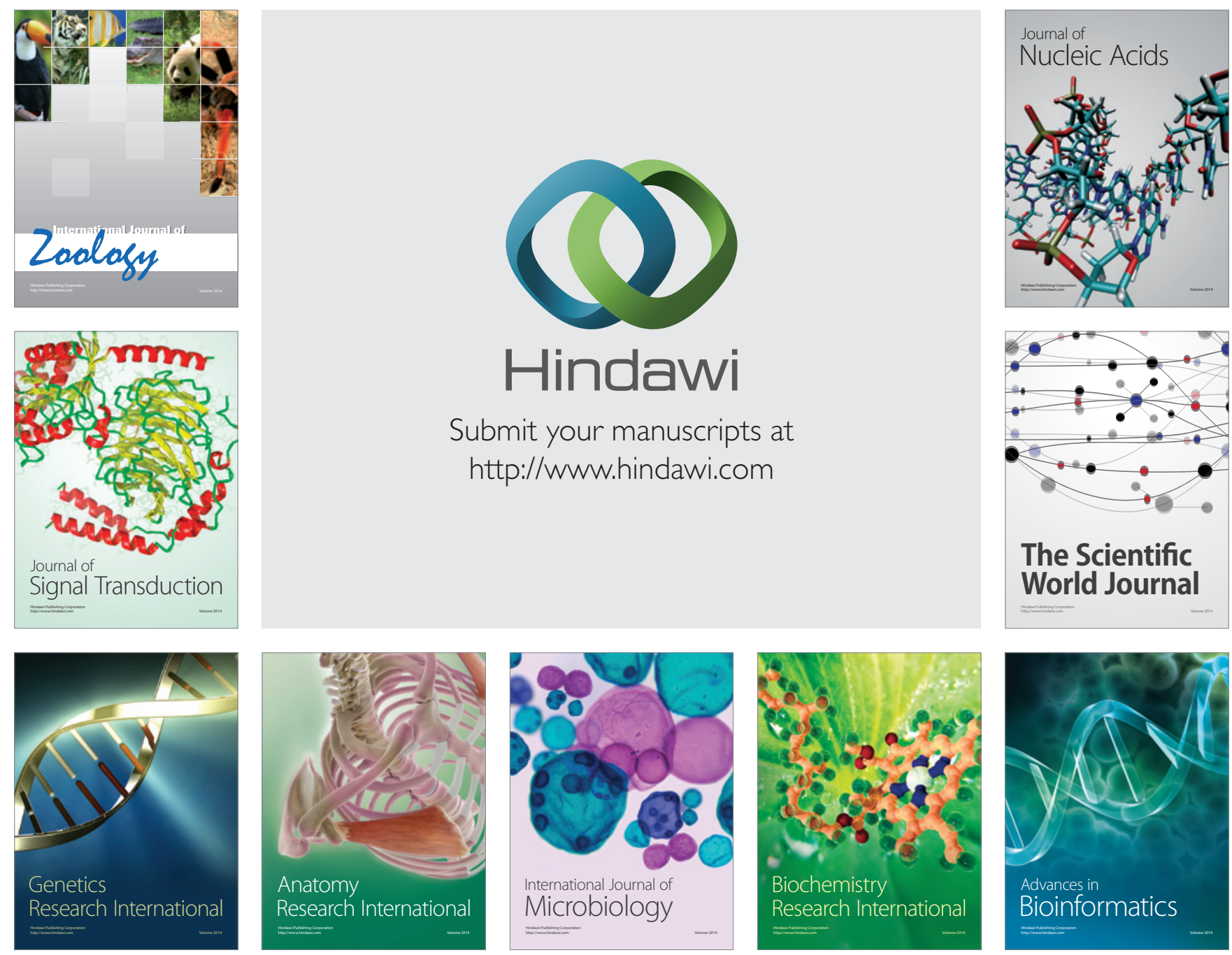

The Scientific World Journal
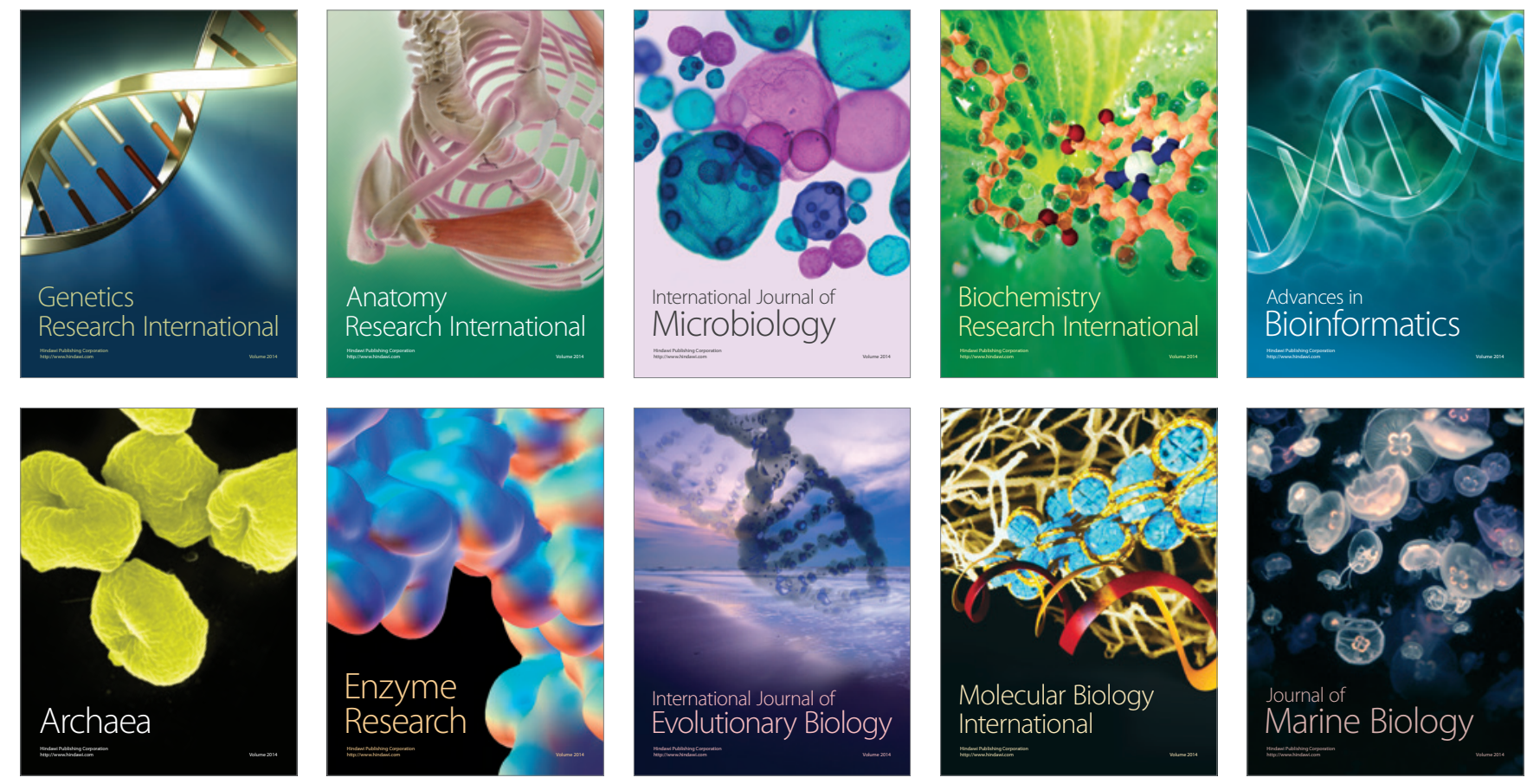